\title{
Antidiuretic hormone regulation in patients with primary nocturnal enuresis
}

\author{
P Eggert, B Kühn
}

\begin{abstract}
Treatment of primary nocturnal enuresis using DDAVP is based upon the hypothesis that antidiuretic hormone (ADH) secretion is insufficient at night. The known efficacy of the treatment on the one hand, and persisting doubts about its theoretical basis on the other, formed the background of the present study. Ten children (mean age 10.5 years) with primary nocturnal enuresis were compared with a corresponding control group of eight patients. Diurnal and nocturnal urine production, ADH secretion, and plasma osmolality were determined. No differences between the two groups were found for urine production, ADH levels during day and night, or plasma osmolality. However, in order to regulate plasma osmolality the enuretic children required a markedly greater output of ADH: $2 \cdot 87$ (95\% confidence interval 0.091 to 40.35$) \mathrm{pg} / \mathrm{ml} / \mathrm{mmol} / \mathrm{kg} v$ $0.56(0.08$ to 1.03$)$ in the controls $(p<0.01)$. The results are consistent with the established fact that ADH secretion is a function of plasma osmolality, and they contradict the hypothesis that urine production is increased at night in enuretics because of lower ADH secretion. The findings do not solve the uncertainties in the pathogenesis of enuresis but they suggest there might be a difference between enuretic children and controls at the ADH receptor level. (Arch Dis Child 1995; 73: 508-511)
\end{abstract}

Keywords: primary nocturnal enuresis, $\mathrm{ADH}$ regulation, DDAVP treatment.

In 1975 George et al described the circadian rhythm of antidiuretic hormone $(\mathrm{ADH})$ secretion with its typical nocturnal rise in serum concentration. ${ }^{1}$ According to the findings of Rittig et al patients with primary nocturnal enuresis do not show this physiological secretion pattern. ${ }^{2}$ On the basis of their findings, these investigators put forward a hypothesis regarding the aetiology of nocturnal bed wetting. This was attractive because it agreed with the concept that enuretic individuals produce high nocturnal urine volumes of low concentration and it suggested a mechanism of treatment, namely substitution of the antidiuretic hormone that is 'lacking' at night. Intranasal administration of DDAVP is very simple. This type of treatment is a little less successful than conditioning alarms ${ }^{3}$ but the use of a nasal spray for therapeutic purposes is much easier to explain to a patient.

The undisputed therapeutic benefits ${ }^{3-5}$ have pushed to the background doubts about the hypothetical lack of $\mathrm{ADH}$ rhythmicity. ${ }^{6}$ It is still uncertain why patients with lowered ADH secretion (neurogenic diabetes insipidus), and thus markedly increased urine volumes, are generally not enuretic. The model can also be criticised for restricting the $\mathrm{ADH}$ secretion mechanism as a function of osmolality in such a way that regulation is effective during the day but not at night in patients with enuresis.

The conflict between the unsatisfactory theoretical basis and the therapeutic efficacy of DDAVP has not been resolved. Our prospective single blind study sought to contribute to a solution.

\section{Methods}

In order to exclude the age dependent aspect in enuresis, the study comprised children from a very narrow age range. It included 10 patients with primary nocturnal enuresis (eight boys, two girls) and eight control children (seven boys, one girl). The age of the enuretic children was 9 years 4 months to 12 years 10 months (median 10 years 6 months), while the age of the children in the control group was 9 years 5 months to 12 years 2 months (median 11 years 2 months). The median body weight in the control group was $35.7 \mathrm{~kg}$ $(27.5-47.0 \mathrm{~kg})$ and $41.7 \mathrm{~kg}(31 \cdot 2-49.3 \mathrm{~kg})$ in the enuretic children. There were no significant differences between enuretics and controls regarding age, weight, sex ratio, and blood pressure. Clinical examination and the following investigation were normal in all children: urea, creatinine, liver enzyme activity, electrolytes, red and white blood cell counts, urine microscopy and culture.

The patients with primary nocturnal enuresis had received no treatment for four weeks before entry to the trial nor did they suffer from other conditions such as abnormalities or infection of the urinary tract. During a two week run-in period, the enuretic children had had at least three wet nights per week. Fluid intake was restricted to $25 \mathrm{ml} / \mathrm{kg} / 24$ hours for three days before the trial and to $20 \mathrm{ml} / \mathrm{kg} / 24$ hours on the day of the study. This fluid management was chosen in order to allow a comparison with the cited studies. ${ }^{2}{ }^{3}$ Urine was collected by spontaneous voiding at the following times: $07,11,15,19,22,01,04$, and 07 hours. Venous blood samples were taken simultaneously by means of an indwelling cannula which had been placed the day before. In order to avoid non-osmotic stimulation of $\mathrm{ADH}$, the blood samples were collected after the patients had been in the supine position for 10 minutes without fluid intake. Blood for the 
$\mathrm{ADH}$ assay was withdrawn into chilled EDTA tubes in iced water. Centrifugation and freezing of the supernatant at $-22^{\circ} \mathrm{C}$ was always done immediately after sampling. $\mathrm{ADH}$ concentration was measured by radioimmunoassay after extraction (Robertson et al ${ }^{7}$ modified according to Rascher $e t a l^{8}$; the measurements were done in Professor Rascher's laboratory, Giessen University Hospital of Paediatrics; the analysts did not know to which group the samples were assigned). Repeated tests and calculation of the mean value were performed in every instance. A Roebling osmometer was used to measure osmolality with repeated tests. The arithmetic means of the measurements at 01, 04, and 07 hours were defined as night values, the means of the figures at 11,15 , and 19 hours as day values.

Enuretic patients were given intranasal DDAVP in a nightly dose of $40 \mathrm{mg}$ for 14 days starting on the day after the examination.

The study was approved by the ethics commitee of Christian-Albrechts-University School of Medicine. After receiving detailed information, the parents gave written consent to the study.

The results are presented as median values and $95 \%$ confidence intervals of the median. Differences were tested using the nonparametric Wilcoxon ranked paired test. The level of significance was set at $p=0 \cdot 1$.

\section{Results}

Before the trial and treatment, enuretic children had 5.2 wet nights per week. Six of the 10 patients responded to treatment. A median of 0.7 wet nights per week was found in these children. There were four non-responders who still had five wet nights per week.

\section{URINE BALANCE}

In the control group, diuresis during the day was $0.63(0.34$ to 1.01$) \mathrm{ml} / \mathrm{kg} /$ hour, while it was 0.77 $(0.50$ to 1.08$) \mathrm{ml} / \mathrm{kg} /$ hour in the enuretic children. Diuresis at night was $0.38(0.26$ to 0.73$)$ $\mathrm{ml} / \mathrm{kg} /$ hour in control children and $0.48(0.30$ to $0.66) \mathrm{ml} / \mathrm{kg} /$ hour in the enuretics. The respective day/night diuresis ratio for the control group was $1.37(0.91$ to 1.85$)$ on average and $1.46(1.18$ to $1.85)$ for the enuretic children. A nocturnal decrease in urine production was evident in both groups, with no difference between controls and enuretic children. Urine osmolality in the control group was 1121.5 (425 to 1161$) \mathrm{mmol} / \mathrm{kg}$ during the day, and rose to 1129.5 (424 to 1232) $\mathrm{mmol} / \mathrm{kg}$ at night. In enuretics the diurnal urine osmolality level was 1057 (870 to 1096) $\mathrm{mmol} / \mathrm{kg}$ and increased to 1091 (868 to 1130 ) $\mathrm{mmol} / \mathrm{kg}$ at night. There was no significant difference between the two groups. An increased urine osmolality at night was found in three controls and six enuretic children, while four controls and four enuretics showed lower osmolalities during the night than in the day.

ANTIDIURETIC HORMONE

The daytime ADH level in the control group was $5.79(1.93$ to 8.07$) \mathrm{pg} / \mathrm{ml}$, which fell to $3.29(1.60$ to $6 \cdot 27) \mathrm{pg} / \mathrm{ml}$ at night. Enuretic children showed a diurnal ADH level of $7 \cdot 60$ $(4.70$ to 11.83$) \mathrm{pg} / \mathrm{ml}$ and a nocturnal one of $5.28(1.37$ to 8.90$) \mathrm{pg} / \mathrm{ml}$. Comparing the day to night ratios in each subject revealed no significant difference between the two groups.

\section{OSMOLALITY}

In the control group plasma osmolality was $286 \cdot 1(285 \cdot 5$ to $291 \cdot 2) \mathrm{mmol} / \mathrm{kg}$ in the daytime and $285.8(278.5$ to $289 \cdot 2) \mathrm{mmol} / \mathrm{kg}$ at night. The day and night plasma osmolalities for the enuretic children were $285.3(282 \cdot 2$ to $286 \cdot 3)$ $\mathrm{mmol} / \mathrm{kg}$ and $284.2(281 \cdot 2$ to $285 \cdot 2) \mathrm{mmol} / \mathrm{kg}$ respectively. The ranked paired test revealed no differences either between day and night or between controls and enuretics.

\section{ADH AND OSMOLALITY}

Figures 1 and 2 show the mean day and night $\mathrm{ADH}$ values for every subject in relation to plasma osmolality. There are two points per subject which are connected by a straight line. The steeper the upward slope, the greater the differences in $\mathrm{ADH}$ levels related to the changes in plasma osmolality. A comparison between the absolute slopes of the controls and the enuretics shows a significantly steeper slope for enuretics $(p<0.01)$. It amounts to $0.56(0.08$ to 1.03$) \mathrm{pg} / \mathrm{ml} / \mathrm{mmol} / \mathrm{kg}$ in the control group and $2.87(0.91$ to 40.35$)$ $\mathrm{pg} / \mathrm{ml} / \mathrm{mmol} / \mathrm{kg}$ in the enuretic group.

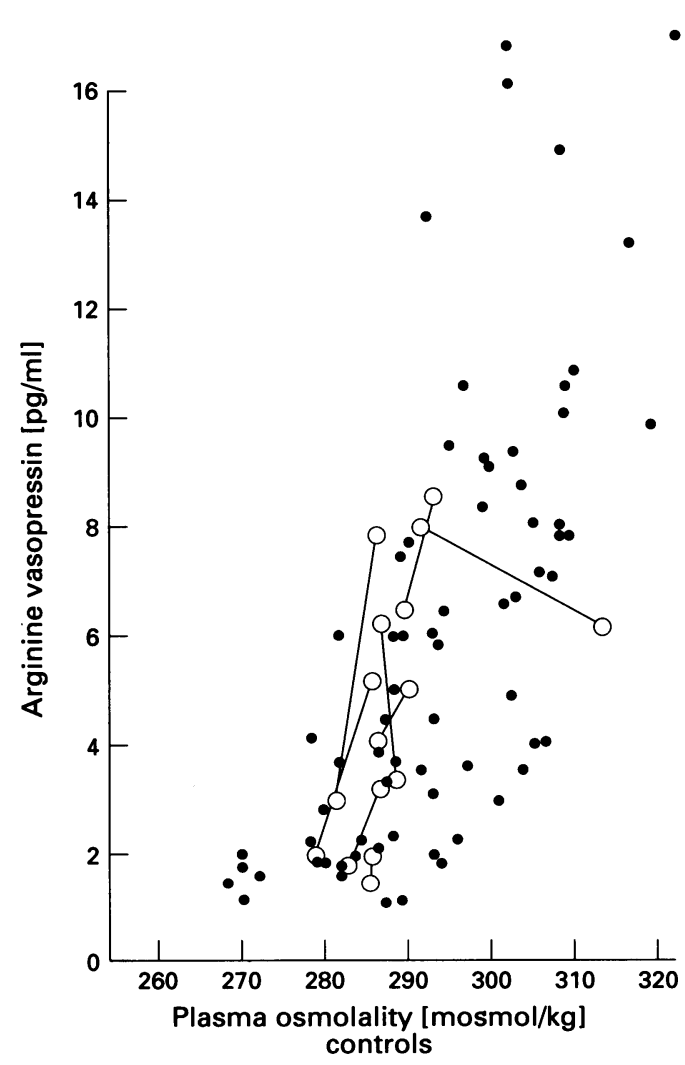

Figure 1 Mean diurnal and nocturnal ADH values for controls. ADH values (empty circles) for each child are connected by a straight line. Dots represent the $A D H$ values in normal children, depending on osmolality, as published by Rascher et al. ${ }^{8}$ 


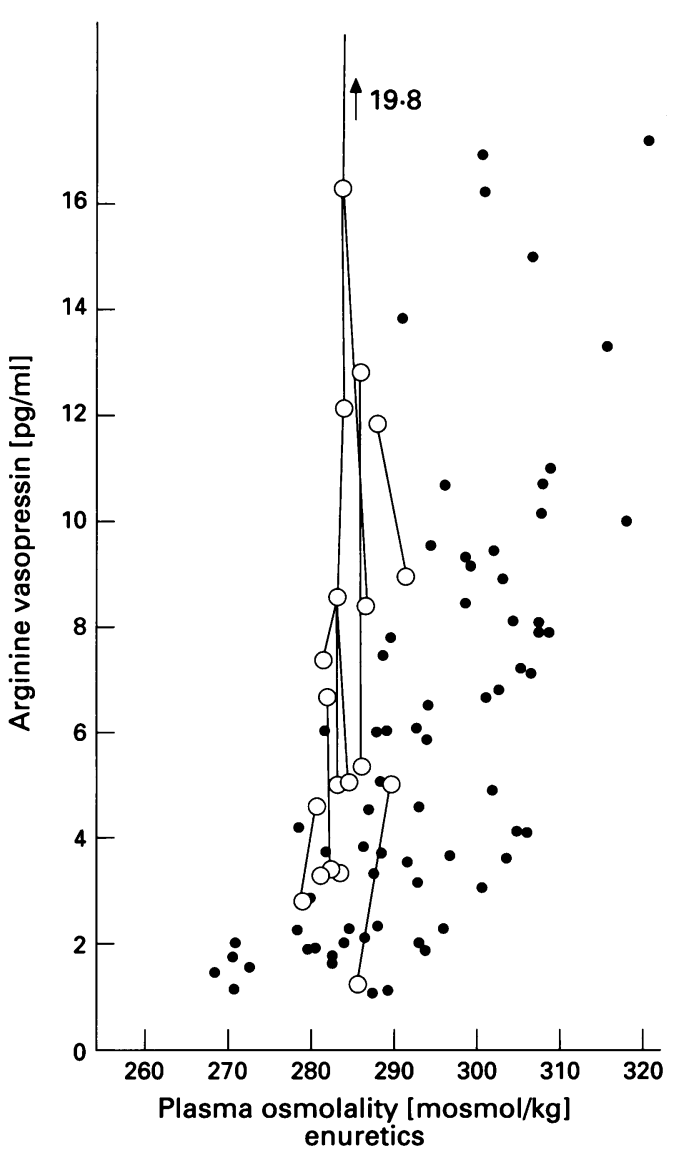

Figure 2 Mean diurnal and nocturnal $A D H$ values for enuretics. See legend to fig 1.

\section{Discussion}

Nocturnal diuresis in patients with enuresis is not increased above that of control patients. Decreased urine production at night was observed in both control and enuretic patients - and bed wetting persisted in the enuretic group. This finding contradicts the widely held notion that increased nocturnal urine production is characteristic of enuretic patients. ${ }^{29} \mathrm{An}$ evaluation of published reports on this subject, however, shows that this is not a novel finding. For example, in 1956, Vulliamy's comprehensive study ${ }^{10}$ found no differences in urine production between enuretic and healthy individuals.

The results of our hormone analyses go against the hypothesis that enuretic individuals lack $\mathrm{ADH}$ rhythmicity, since the enuretic and non-enuretic groups showed no differences in diurnal and nocturnal $\mathrm{ADH}$ activity.

Circadian rhythm of $\mathrm{ADH}$ secretion was first described by George et al. ${ }^{1}$ These investigators observed a nocturnal increase in $\mathrm{ADH}$ activity in eight out of 10 adults and related these findings to the circadian rhythm in urine output noted by Mills in $1959 .{ }^{11}$ It is, of course, tempting to attribute a nocturnal increase in urine production to a lack of rise in nocturnal $\mathrm{ADH}$ secretion. The increased urine output would then lead to enuresis once bladder capacity is exceeded. This explanation, however, does not account for the fact that such $\mathrm{ADH}$ rhythmicity was only demonstrated in subjects who were left in absolute quiet in a horizontal position without any fluid intake. It is therefore quite likely that this effect plays no part, or only a very minor one, in normally active individuals.

Contrary to the anticipated nocturnal increase in $\mathrm{ADH}$, we found a daytime rise in $\mathrm{ADH}$ in all children, enuretic and nonenuretic. This finding may seem surprising but the children were probably so active in the air conditioned rooms of the ward that cutaneous fluid loss reached a point where it became necessary to regulate excretion by an increase in $\mathrm{ADH}$. The results show that both enuretic and control children were able to do so, reaching constant plasma osmolality.

There is one major difference between the two groups. Enuretic children required substantially greater changes in $\mathrm{ADH}$ secretion to regulate osmolality than control patients (figs 1 and 2). It is well known that $\mathrm{ADH}$ secretion depends on plasma osmolality. ${ }^{812}$ The steepness of the correlation curve described varies in different studies, ranging from 0.2 to 0.65 $\mathrm{pg} / \mathrm{ml} / \mathrm{mmol} / \mathrm{kg} .^{13}$ The values for our control group were in this range. The increases in the enuretic group, on the other hand, differed markedly $(2 \cdot 87 \mathrm{pg} / \mathrm{ml} / \mathrm{mmol} / \mathrm{kg})$. Even though the study contained relatively few patients and controls, this difference was significant $(\mathrm{p}<0.01)$.

Our findings do not solve uncertainties regarding the pathogenesis of enuresis. They do, however, provide evidence against the concept that enuretic individuals have an increased urine volume at night, and they disprove the hypothesis that the capacity to regulate osmolality by adequate $\mathrm{ADH}$ secretion is reduced during the night. Our results furnish evidence that the regulating function of $\mathrm{ADH}$ secretion differs between enuretic and nonenuretic children. This may be the explanation for the established efficacy of DDAVP treatment. The well known familial disposition towards nocturnal enuresis and the fact that there is a high rate of spontaneous resolution with age are in keeping with this finding because the extent to which $\mathrm{ADH}$ secretion and osmolality correlate differs from person to person and also depends on age. ${ }^{14}$ The results of this study lead us to speculate that there might be a difference between enuretic children and controls at the $\mathrm{ADH}$ receptor level.

1 George CPL, Messerli FH, Genest J, et al. Diurnal variations of plasma vasopressin in man. 7 Clin Endocrinol Metab 1975; 41: 332-8.

2 Rittig $S$, Knudsen UB, Nørgaard JP, Pedersen EB, Djurhuus JC. Abnormal diurnal rhythm of plasma vasopressin and urinary output in patients with enuresis. $A m \mathcal{F}$ pressin and urinary outp

3 Moffatt MEK, Harlos S, Kirshen AJ, Burd L. Desmopressin acetate and nocturnal enuresis: how much do we know? acetate and nocturnal enuresi

4 Dimson SB. DDAVP and urine osmolality in refractory enuresis. Arch Dis Child 1986; 61: 1104-7.

5 Evans JHC, Meadow SR. Desmopressin for bed wetting: length of treatment, vasopressin secretion, and response. Arch Dis Child 1992; 67: 184-8.

6 Feffermann RA. DDAVP approval question. Pediatrics 1994; 93: 1022-3.

7 Robertson GL, Mahr EA, Athar S, Sinha T. Developmen and clinical application of a new method for the radioimmunoassay of arginine-vasopressin in human plasma f Clin Invest 1973; 52: 2340-52

8 Rascher W, Rauh W, Brandeis WE, Huber KH, Schärer K Determinants of plasma arginine-vasopressin in children 
Acta Paediatr Scand 1986; 75: 111-7.

9 Nørgaard JP, Pedersen EB, Djurhuus JC. Diurnal antidiuretic-hormone levels in enuresis. $\mathcal{F}$ Urol 1985; 134: 1029-31.

10 Vulliamy $D$. The day and night output of urine in enuresis. Arch Dis Child 1956; 31: 439-43.

11 Mills JN. Diurnal rhythm in urine flow. $f$ Physiol (Lond) 1951; 113: 528-36

12 Thompson CJ, Bland J, Burd J, Baylis PH. The osmotic thresholds for thirst and vasopressin release are similar in healthy man. Clin Sci 1986; 71: 651-6.

13 Baylis PH, Thompson CJ. Osmoregulation of vasopressin secretion and thirst in health and disease. Clin Endocrinol 1988; 29: 549-76.

14 Helderman JH, Vestal RE, Rowe JW, Tobin JD, Andres R, Robertson GL. The response of arginine vasopressin to intravenous ethanol and hypertonic saline in man. f Gerontol 1978; 33: 39-47. 